\title{
OPERATION OF HYBRID WIND FARM BASED ON SCIG AND DFIG UNDER GUST WIND SPEED
}

\author{
Omar Noureldeen ${ }^{1}$, M. A. abdelwahab ${ }^{2}$ and Ahmed Rashad ${ }^{3}$ \\ ${ }^{l}$ Electrical Engineering Department, Faculty of Engineering, Qena, South \\ Valley University, Egypt \\ ${ }^{2}$ Electrical Engineering Department, Faculty of Engineering, Menia \\ University, Egypt \\ ${ }^{3}$ Rural Electrification Authority in Egypt (REA) \\ e-mail: omar_noureldeen@svu.edu.eg
}

(Received April 21, 2011 Accepted May 31, 2011)

\begin{abstract}
The continuous increasing in the pollution level and in the same time increasing in fuel price are factors which lead to the increase in using renewable energy sources specially wind energy. Wind energy faces many challenges, one of the important challenges is that of the rapidly change in wind speed which depends on the weather condition. A change in wind speed affects on the generated power from wind turbine. SCIG and DFIG are famous kinds of wind turbine, Each of them has advantage and disadvantage, SCIG is cheap but its operation has a great effect on system stability, especially when it operates without static synchronous compensator. DFIG keeps the system stable but it is very expensive. Therefore, it's necessary to examine the response of different wind turbine generators variation of gust wind speed. This paper investigates the ability of hybrid wind farm which consists of SCIG and DFIG to operate without static synchronous compensator under gust wind speed condition. The gust wind speed is simulated according to the International Electrotechnical Commission IEC 61400.
\end{abstract}

KEYWORDS: Wind Farm, Wind Speed STATCOM, SCIG, DFIG.

\begin{tabular}{|llll|}
\hline \multicolumn{3}{|c|}{ NOMENCLATURE } \\
$i_{d s}$ & d- axis stator current & $R_{s}$ & stator resistance,$\Omega$ \\
$i_{d r}$ & d- axis rotor current & $R_{r}$ & rotor resistance,$\Omega$ \\
$i_{q s}$ & q- axis stator current & $v_{d s}$ & d-axis stator voltage \\
$i_{q r}$ & q- axis rotor current & $v_{d r}$ & d- axis rotor voltage \\
$L_{m}$ & the magnetizing inductance, $\mathrm{H}$ & $v_{q r}$ & q-axis rotor voltage \\
$L_{S L}$ & the stator leakage inductance, $\mathrm{H}$ & $v_{q r}$ & q-axis stator voltage \\
$L_{r L}$ & the rotor leakage inductance, $\mathrm{H}$ & $\omega_{r}$ & the electric rotor speed \\
\hline
\end{tabular}

\section{INTROUCTION}

The increased penetration of wind energy into the power system over the last decade generates new challenges for the power system operators, who have to ensure a reliable 
and a safe grid operation. At the same time the high penetration of wind farm into the grid may have some impact on network stability during steady state and disturbance conditions. In the fixed speed wind turbine generator which uses Squirrel Cage Induction Generator (SCIG), when the wind speed is increased the absorbed reactive power is increased, so that it is necessary to use STATCOM to make a suitable dynamic reactive power compensation and keep the voltage of the grid at its allowed level. On other side, the wind turbine generator which uses Double Feed Induction Generator (DFIG) is more stable during wind speed variations, but the DFIG is very expensive with respect to SCIG [1-3]. The problem is that, using the STATCOM in fixed speed wind turbines is limited by its design and its rate of reactive power. On other side, the expensive of DFIG technology is big problem which may face many countries, including Egypt, This paper tries to overcome this problem by designing a hybrid wind farm which consists of SCIGs and DFIGs without STATCOM connecting to the SCIGs terminals. Half of the studied hybrid wind farm generators is SCIGs and the other half is DFIGs.

\section{MODELING OF WIND TURBINE}

\subsection{Mechanical Power}

A wind turbine catches the wind through its rotor blades and transfers it to the rotor hub. The rotor hub is attached to a low speed shaft through a gear box. The high speed shaft drives an electric generator which converts the mechanical energy to electrical energy and delivers it to the grid [4]. As the wind speed varies, the power captured, converted and transmitted to the grid also varies.

$$
P_{m}=\frac{1}{2} \rho \pi r^{2} V^{3} C_{p}
$$

where $P_{m}$ is the mechanical power of wind turbine, $\rho$ is the air density (nominally $\left.1.22 \mathrm{Kg} / \mathrm{m}^{3}\right), r$ is the radius of area swept by the turbine blades, $V$ is the wind speed, and $C_{p}$ is the coefficient performance of the wind turbine. Power coefficient of wind turbine $C_{p}$ is given by the next equation [5]:

$$
C p(\beta, \lambda)=0.5173\left(\frac{116}{\lambda i}-0.4 \beta-5\right) e^{\frac{-0.0068}{\lambda i}}+0.0086 \lambda
$$

where,

$$
\frac{1}{\lambda i}=\frac{1}{\lambda+0.08 \beta}-\frac{0.035}{\beta^{3}+1}
$$

where $\beta$ is the bitch angle of the blade in degree and $\lambda$ is the tip speed ratio, it is given by the following equation:

$$
\lambda=\frac{\omega r}{V}
$$

where $\omega$ is the angular speed of the turbine. 


\subsection{Electrical Modeling of SCIG and DFIG}

This part illustrates the modeling of SCIG and DFIG that had been used in this study. The modeling of induction generator is the same as general modeling of induction machine where all quantities of the stator and rotor are decomposed in two axis references $(d-q$ frame) and all electrical parameters of rotor and stator are referred to the stator. The following equations represent the general modeling of induction generator $[6,7]$.

$$
\left[\begin{array}{c}
v_{q s} \\
v_{d s} \\
v_{q r} \\
v_{d r}
\end{array}\right]=\left[\begin{array}{cccc}
R_{S}+p L_{S} & 0 & p L_{m} & 0 \\
0 & R_{S}+p L_{S} & 0 & p L_{m} \\
p L_{m} & -\omega_{r} L_{m} & R_{r}+p L_{r} & \omega_{r} L_{r} \\
\omega_{r} L_{m} & p L_{m} & \omega_{r} L_{r} & R_{r}+p L_{r}
\end{array}\right]\left[\begin{array}{c}
i_{q s} \\
i_{d} \\
i_{q r} \\
i_{d r}
\end{array}\right]
$$

where, $L_{S}=L_{S L}+L_{m}, L_{r}=L_{r}+L_{m}$.

For SCIG the above equation can be transferred into the next equation.

$$
\left[\begin{array}{l}
v_{q s} \\
v_{d s} \\
0 \\
0
\end{array}\right]=\left[\begin{array}{cccc}
R_{S}+p L_{S} & 0 & p L_{m} & 0 \\
0 & R_{S}+p L_{s} & 0 & p L_{m} \\
p L_{m} & -\omega_{r} L_{m} & R_{r}+p L_{r} & \omega_{r} L_{r} \\
\omega_{r} L_{m} & p L_{m} & \omega_{r} L_{r} & R_{r}+p L_{r}
\end{array}\right]\left[\begin{array}{l}
i_{q s} \\
i_{d s} \\
i_{q r} \\
i_{d r}
\end{array}\right]
$$

For DFIG the general equation of induction generator can be transferred into the next equation.

$$
\left[\begin{array}{c}
v_{q s} \\
v_{d s} \\
v_{q r} \\
v_{d r}
\end{array}\right]=\left[\begin{array}{cccc}
R_{S}+p L_{s} & 0 & p L_{m} \cos \theta_{r} & -p L_{m} \sin \theta_{r} \\
0 & R_{S}+p L_{s} & p L_{m} \sin \theta_{r} & p L_{m} \cos \theta_{r} \\
p L_{m} \cos \theta_{r} & p L_{m} \sin \theta_{r} & R_{r}+p L_{r} & 0 \\
-p L_{m} \sin \theta_{r} & p L_{m} \sin \theta_{r} & 0 & R_{r}+p L_{r}
\end{array}\right]\left[\begin{array}{c}
i_{q s} \\
i_{d s} \\
i_{q r} \\
i_{d r}
\end{array}\right]
$$

The flux linkage of the stator and the rotor according to reference ( $d-q$ frame) can be defined by [8]

$$
\left.\begin{array}{l}
\Phi_{q s}=L_{s} \times i_{q s}+L_{m} \times i_{q r} \\
\Phi_{d s}=L_{s} \times i_{d s}+L_{m} \times i_{d r} \\
\Phi_{q r}=L_{r} \times i_{q r}+L_{m} \times i_{q s} \\
\Phi_{d r}=L_{r} \times i_{d r}+L_{m} \times i_{d s}
\end{array}\right\}
$$

By the above equations of flux linkage, the electrical torque can be calculated by using the next equation [9].

$$
T_{e}=\frac{3}{2} N\left(\Phi_{d s} \times i_{q s}-\Phi_{q s} \times i_{d s}\right)
$$

Where $N$ is the number of pair poles

For DFIG the same matrix is used the same flux linkage equations and the same voltage equations except $v_{q r}$ and $v_{d r}$ are not zero because the DFIG uses a wound rotor which it is connected to $\mathrm{AC} / \mathrm{DC} / \mathrm{AC}$ converter through slip rings and brushes. This reason will make the difference in electrical torque equation. 


$$
T_{e}=-N \frac{L_{m}}{L_{S}}\left(\Phi_{q s} \times i_{d r}-\Phi_{d s} \times i_{q r}\right)
$$

The schematic diagrams of the SCIG and DFIG used in the simulation are shown in Figure 1.

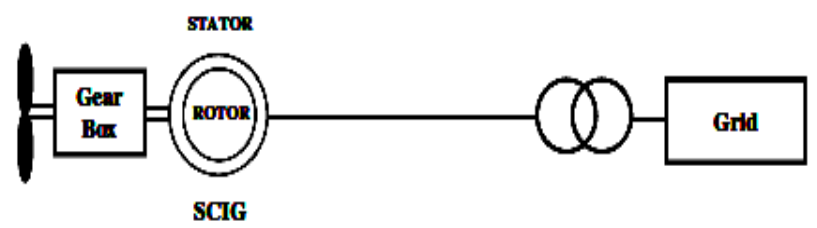

(a) SCIG

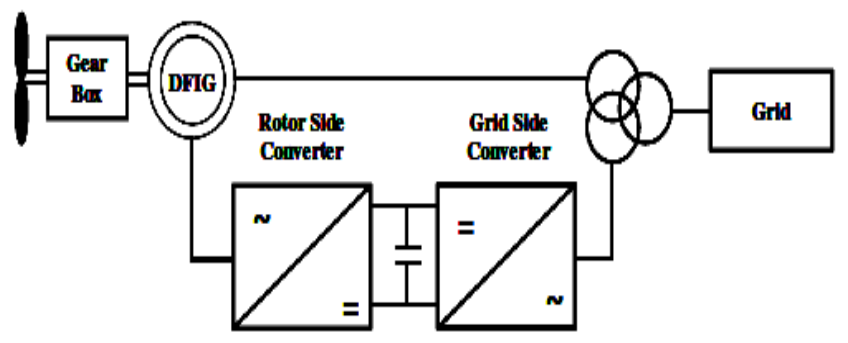

(b) DFIG

Figure 1. Schematic diagrams of the SCIG and DFIG

\section{WIND SPEED SIMULATION}

The extreme wind conditions are simulated according to IEC 61400 to determine extreme wind loads on wind turbine generators. These conditions include peak wind speeds due to storms and rapid changes in wind speed. The wind speed is defined by the following equation [10]:

$$
V(Z, t)=\left[\begin{array}{ll}
V(Z)-0.37 V_{\text {gust }}\left(\sin \left(\frac{3 \pi t}{T}\right)\right)\left(1-\cos \left(\frac{2 \pi t}{T}\right)\right) & \text { for } \rightarrow 0 \leq t \leq T \\
V(Z) & \text { for } \rightarrow 0<t>T
\end{array}\right]
$$

where $V(Z)$ is the wind speed at height $Z$ above the ground and $T$ is equal 10.5 second. The gust wind speed $V_{\text {gust }}$ can be given by:

$$
V_{\text {gust }}=\frac{4.8 \delta}{1+0.1 \frac{D}{A}}
$$

where $\delta$ is the standard deviation of longitudinal wind velocity, $D$ is the rotor diameter and $A$ is the turbulence scale parameters.

Equations (10) and (11) are simulated using MATLAB Simulink toolbox as shown in Fig. 2. The simulated wind speed curve which reflects the extreme gust wind speed variation according to IEC 61400 is shown in Fig. 3. 


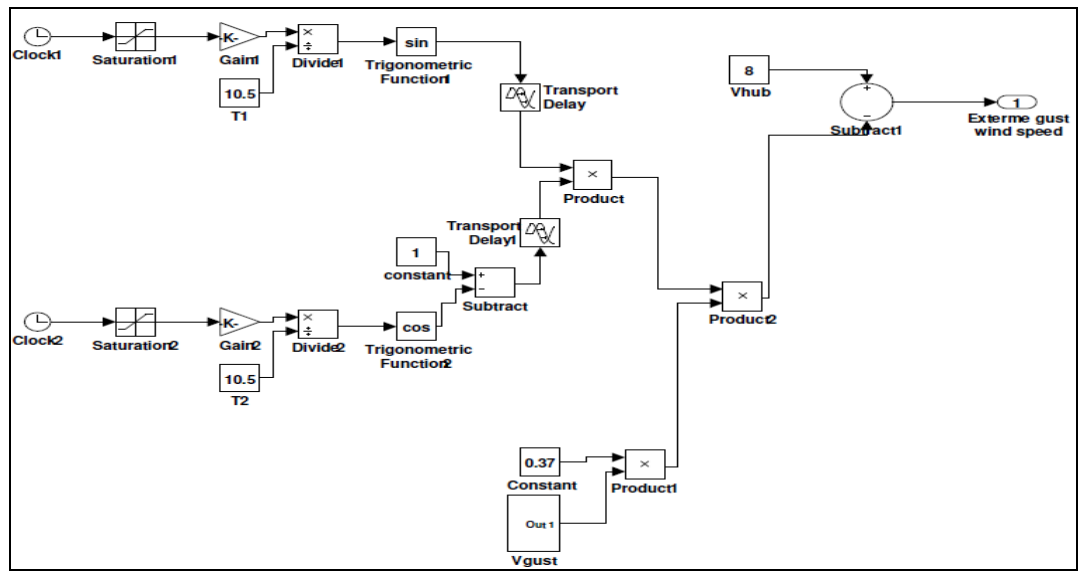

Figure 2. The SIMULINK model of wind speed variation.

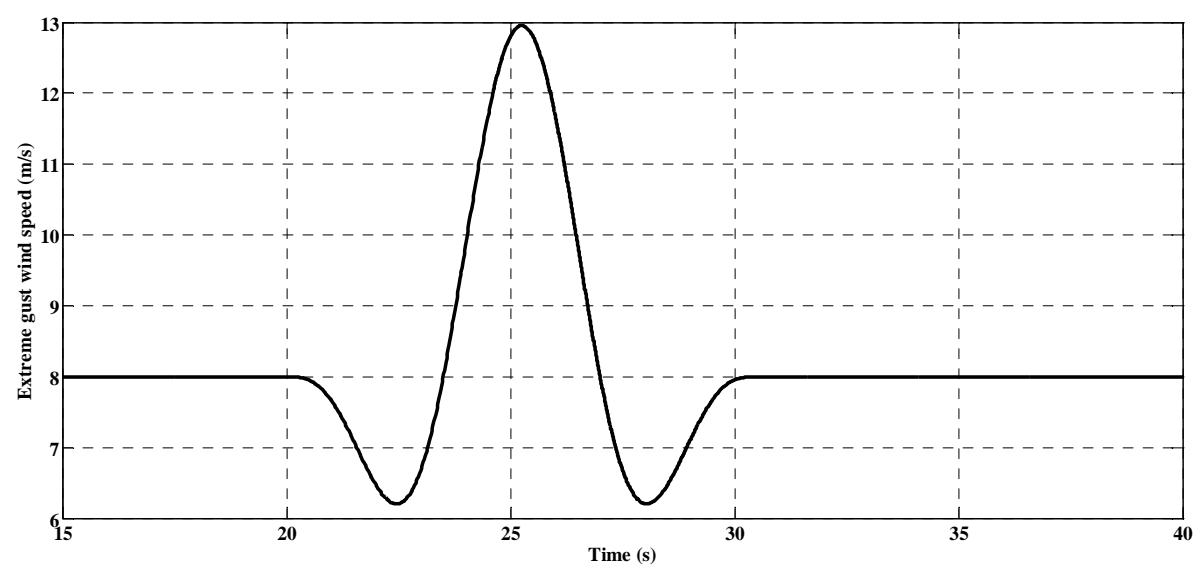

Figure 3. Extreme gust wind speed variation according to IEC 61400.

\section{CASE STUDY}

Figure 4 shows the single line diagram of the studied system which consists of a wind farm connected to $120 \mathrm{kV}$ grid via $25 \mathrm{kV}, 30 \mathrm{~km}$ transmission line. The studied wind farm consists of six 1.5 MW generators. To study the effect of gust wind speed on the stability of wind farm interconnected grid, the simulation is performed for different cases. In the first case, all the wind farm generators are SCIGs connected with a 3 MVAR STATCOM. In the second case, all the wind farm generators are DFIGs. In the third case, the hybrid wind farm consists of an equal number of SCIGs and DFIGs. In the fourth case, the capacity of the hybrid wind farm is increased from 9 MW to 12 MW and then to $18 \mathrm{MW}$. The wind farm generated power, the absorbed reactive power, and the wind farm terminal voltage are monitored for all studied cases. 


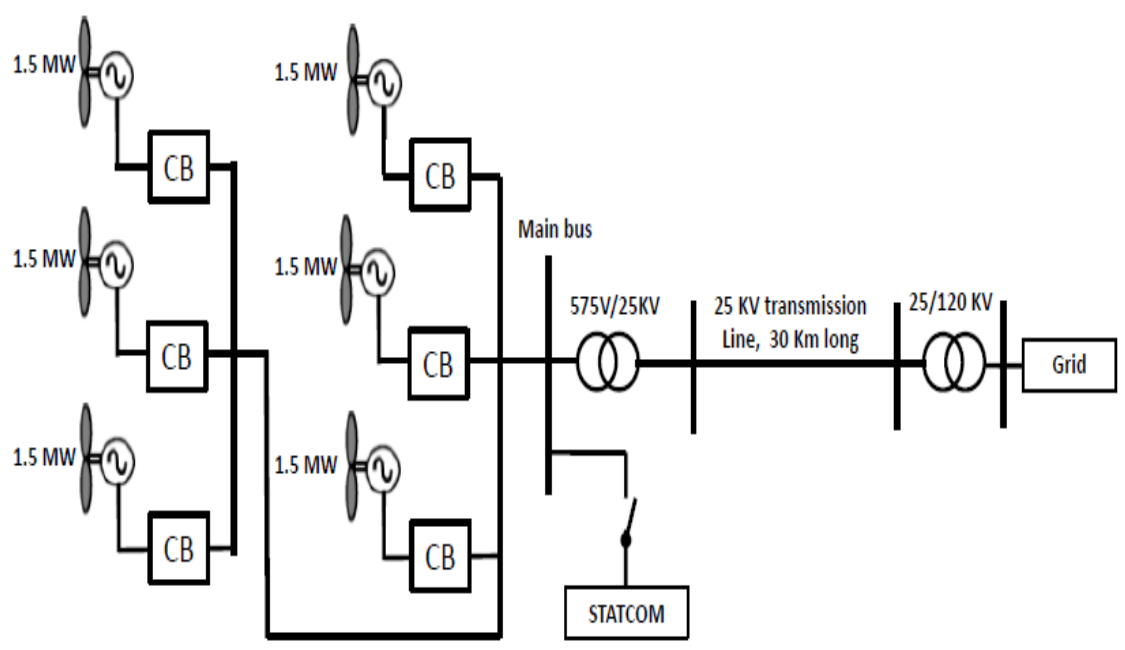

Figure 4. Single line diagram of the studied system

Each wind turbine has a protection system which monitors: Instantaneous AC over current, $\mathrm{AC}$ over current (positive sequence), $\mathrm{AC}$ current unbalance, $\mathrm{AC}$ under voltage (positive sequence), AC over voltage (positive sequence), AC voltage unbalance (negative sequence), AC voltage unbalance (zero sequence), DC over voltage, under speed and over speed. The protection set parameters are illustrated at Table 1.

Table 1: Protection system set parameters.

\begin{tabular}{|l|c|c|c|}
\hline \multicolumn{4}{|c|}{ AC voltage and rotor speed protection } \\
\hline Parameter & $\begin{array}{c}\text { Minimum } \\
\text { Value (pu) }\end{array}$ & $\begin{array}{c}\text { Maximum value } \\
(\mathbf{p u})\end{array}$ & Delay time (sec) \\
\hline AC under/over voltage & 0.75 & 1.1 & 0.1 \\
\hline Under/over rotor speed & 1 & 1.05 & 5 \\
\hline \multicolumn{2}{|c|}{ AC current and DC voltage protection } \\
\hline Parameter & Maximum value & Delay time (sec) \\
\hline AC current & $1.1 \mathrm{pu}$ & 10 \\
\hline AC current unbalance & 0.4 & 0.2 \\
\hline voltage unbalance & $0.05 \mathrm{pu}$ & 0.2 \\
\hline DC voltage & $1900 \mathrm{v}$ & 0.001 \\
\hline
\end{tabular}

\section{SIMULATION RESULTS}

\subsection{Effect of Generator Types}

Figures 5, 6 and 7 show the variations of active power, reactive power and terminal voltage in case of gust wind speed for different wind farms. In case of SCIG wind farm during steady state period of wind speed, the generated active power is $5.8 \mathrm{MW}$. When the wind speed decreases, the active power is decreased to 1.1 MW and it is increased 
to $12.5 \mathrm{MW}$ by increasing the wind speed. At the same time, the absorbed reactive power increases by increasing the wind speed and the wind farm terminal voltage falls to zero, where the STATCOM becomes unable to compensate the absorbed reactive power by SCIGs. Therefore, the SCIG wind farm cannot stay connected to the grid and the protection system trips it. Figure 6 shows that, there is some increase of the terminal bus voltage after wind farm outage, this increase is due to the reactive power injected by STATCOM.

In case of DFIG wind farm during steady state period, the generated active power is 6.16 MW. The generated active power varies between 5.3 MW and 8.6 MW by decreasing and increasing of wind speed. The variation of absorbed reactive power from the grid is very little due to the operation of $\mathrm{AC} / \mathrm{DC} / \mathrm{AC}$ converter which keeps the reactive power of DFIG independent of the output power. Also, the wind farm terminal voltage is not affected by gust wind speed variation. In case of hybrid wind farm, the generated active power is $5.93 \mathrm{MW}$ during steady state operation. The generated active power varies between $3.43 \mathrm{MW}$ and $9.81 \mathrm{MW}$ according to the variations of wind speed. Also, the wind farm terminal voltage is not affected by gust wind speed and there is a small variation in the absorbed reactive power. It is clear that, the system can return to steady state operation in case of hybrid wind farm and in case of DFIG wind farm. Also, the SCIGs can stay in operation during gust wind speed when it operates with the DFIGs as a hybrid wind farm.

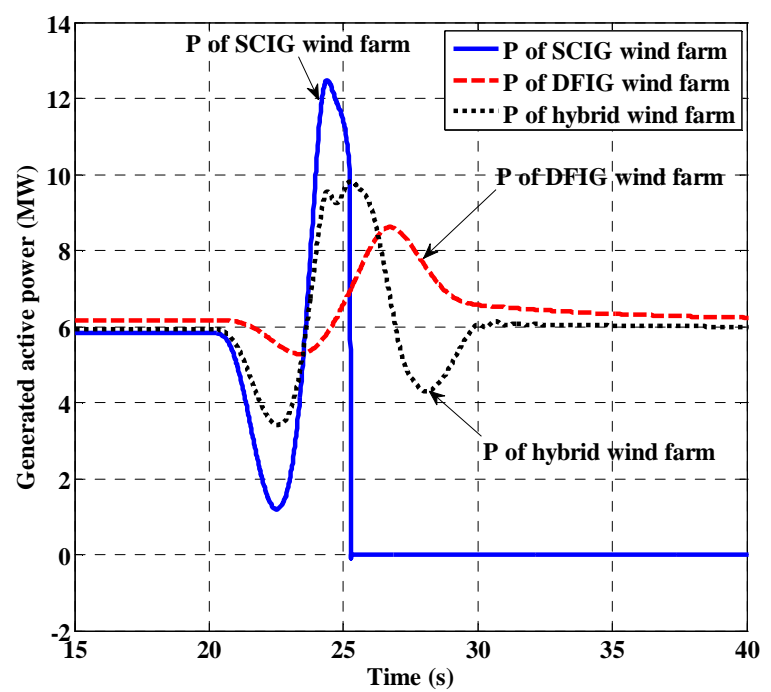

Figure 5. The generated power of SCIG, DFIG and hybrid wind farms 


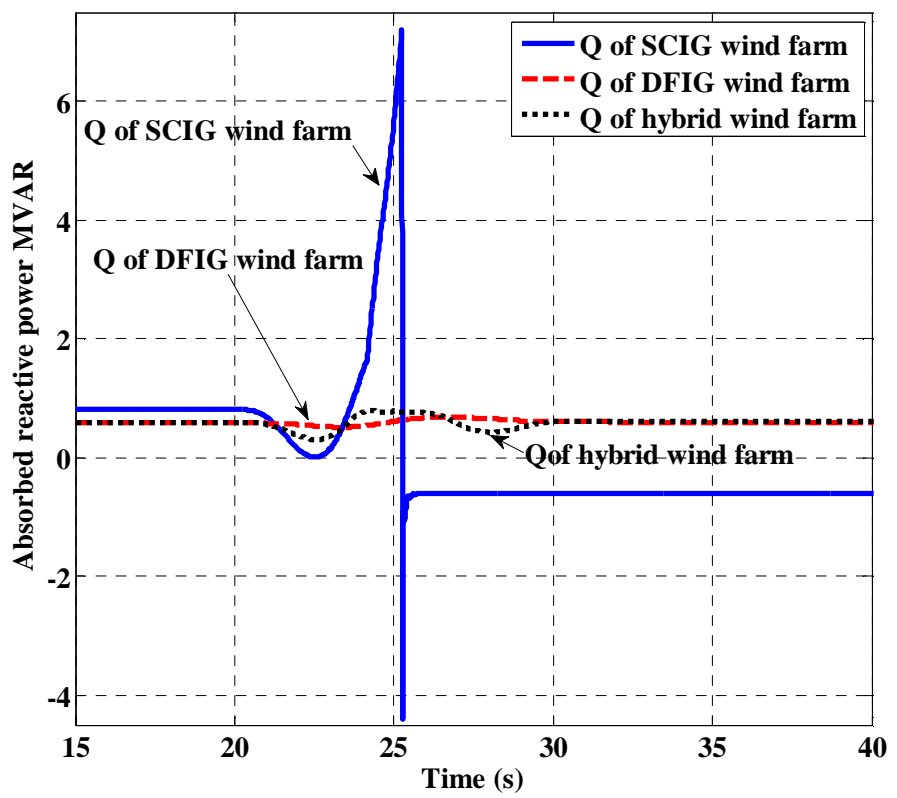

Figure 6. The reactive power of SCIG, DFIG and hybrid wind farms

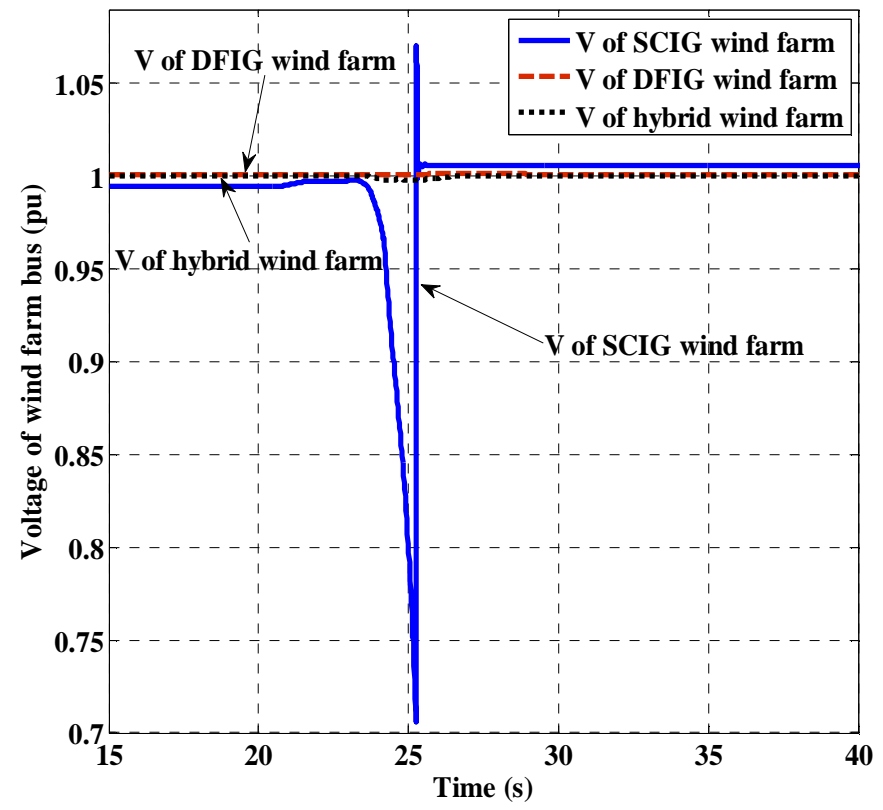

Figure 7. The voltage of bus $575 \mathrm{~V}$ of SCIG, DFIG and hybrid wind farms

\subsection{Effect of Hybrid Wind Farm Capacity}

To study the effect of gust wind speed on the stability of hybrid wind farms with different capacities, the hybrid wind farm capacity is increased to $12 \mathrm{MW}$ and then to $18 \mathrm{MW}$ as shown in Figures 8 and 9. This capacity is increased by increasing the number of wind farm generators, where the power of each of them is $1.5 \mathrm{MW}$. 


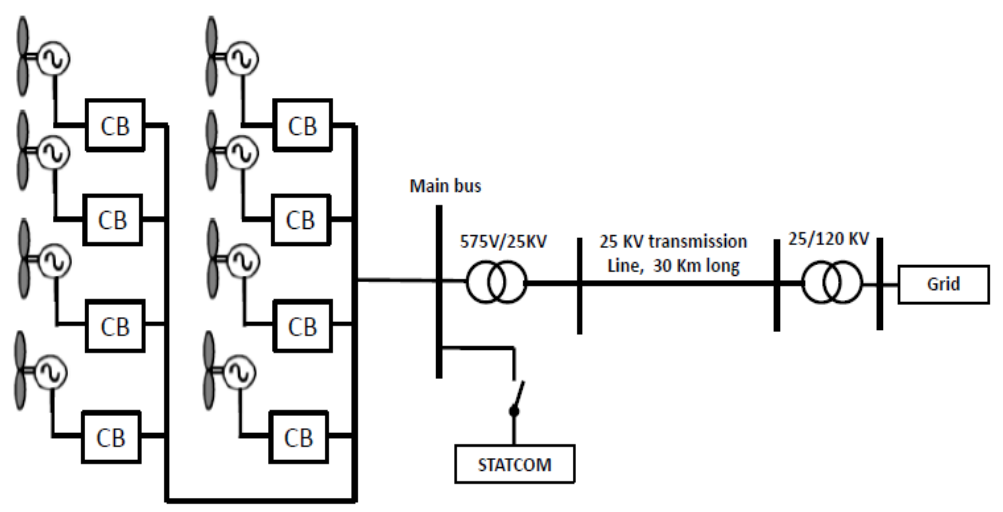

Figure 8 . The single line diagram of $12 \mathrm{MW}$ hybrid wind farm

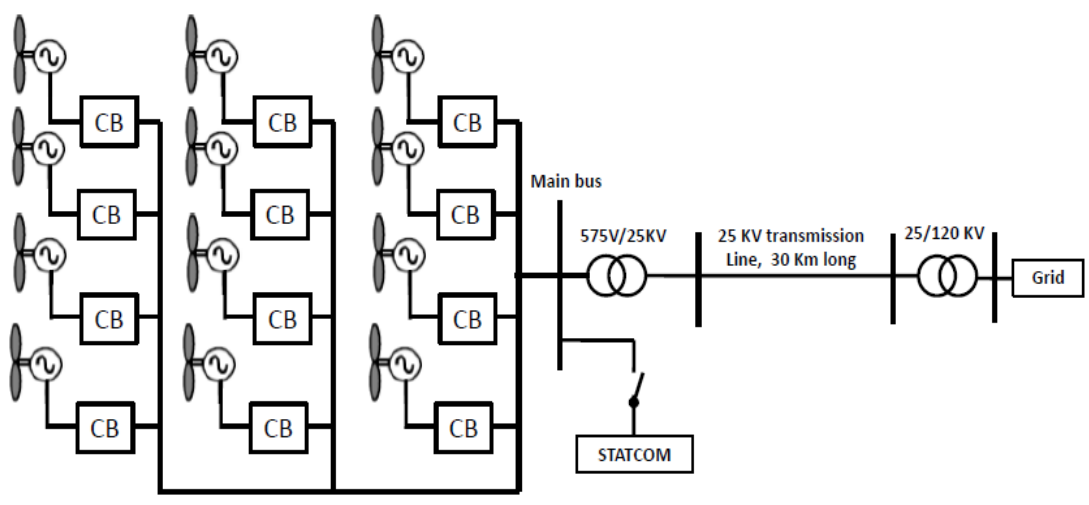

Figure 9. The single line diagram of $18 \mathrm{MW}$ hybrid wind farm

Figures 10,11, and 12 show the variations of active power, reactive power and terminal voltage when the wind farm capacity is increased. Figure 10 shows that, the generated active power is varied according to gust wind speed variations. It is clear that, the wind farm can return to steady state condition after the demise of the storm. In case of steady state condition, when the wind farm capacity is increased the absorbed reactive power from the grid is decreased where the absorbed reactive power is compensated by AC/DC/AC converter. Figure 11 shows that, in case of 9 and $12 \mathrm{MW}$ wind farms, the absorbed reactive power by the wind farm is proportional to its output power and wind speed variation. In case of $18 \mathrm{MW}$ wind farm, when the wind speed is decreased, the reactive power absorbed by SCIGs is increased, where the reactive power injected by AC/DC/AC converter is not sufficient. During increasing of wind speed, the variations of absorbed reactive power by 9 and $12 \mathrm{MW}$ wind farms are not obvious. In case of $18 \mathrm{MW}$ wind farm, the absorbed reactive power is decreased by increasing the wind speed, and then the generated reactive power by AC/DC/AC converter is injected to the grid to keep the terminal voltage at its nominal value. It is obvious that the hybrid wind farm can operate under gust wind speed without the connecting of STATCOM to SCIGs. The AC/DC/AC converter can operate as a reactive power support of the wind farms. 


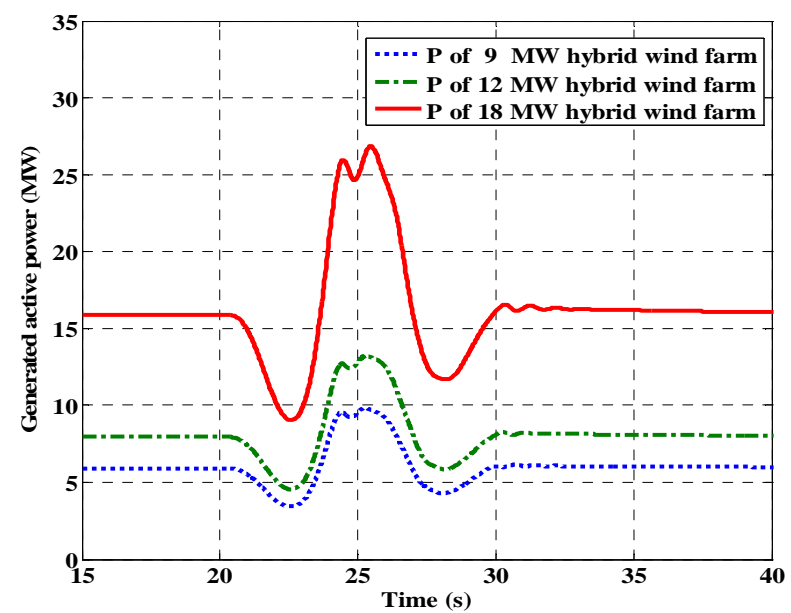

Figure 10. The output power of the hybrid wind farm

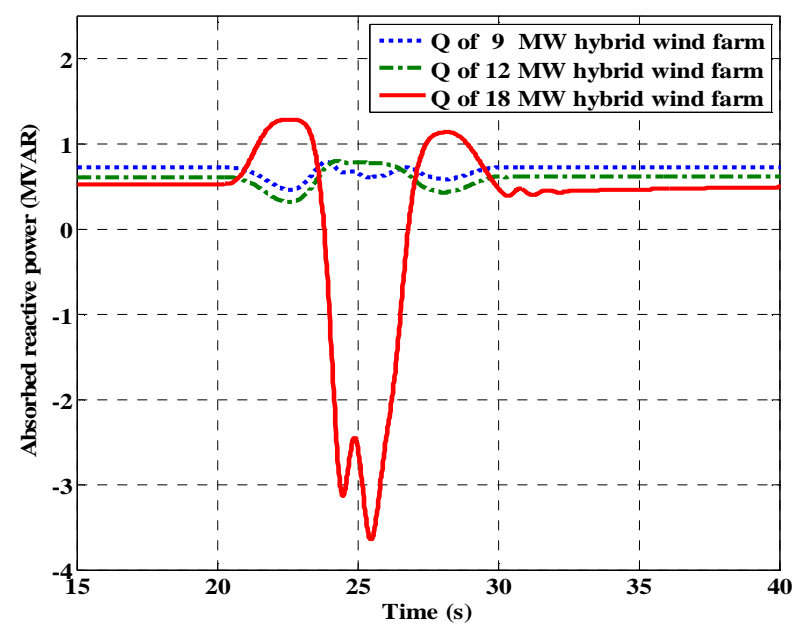

Figure 11. The reactive power of the hybrid wind farm

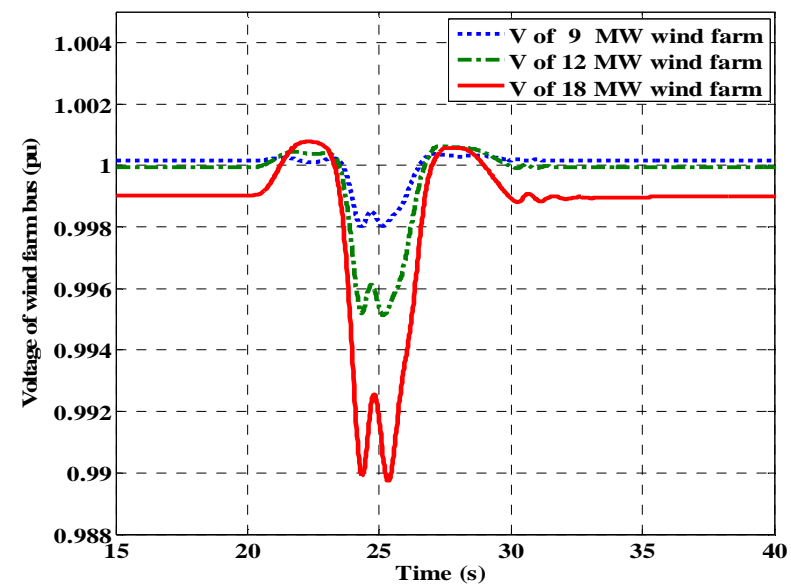

Figure 12. The Voltage of bus $575 \mathrm{~V}$ of the hybrid wind farm 


\section{CONCLUSION}

The impacts of gust wind speed variations on hybrid wind farm connected to grid in case of using SCIGs and DFIGs are investigated. The simulation of wind speed variation according to IEC 61400 is investigated. The simulation is performed for different cases. In the first case, all the wind farm generators are SCIGs connected with a 3 MVAR STATCOM. In the second case, all the wind farm generators are DFIGs. In the third case, the hybrid wind farm consists of an equal number of SCIGs and DFIGs. In the fourth case, the capacity of the wind farm is increased from $9 \mathrm{MW}$ to $12 \mathrm{MW}$ and then to $18 \mathrm{MW}$. The wind farm generated power, the absorbed reactive power, and the wind farm terminal voltage are monitored for all the studied cases. It is clear that, the wind farm which use SCIG cannot stay connected to the grid under gust wind condition. In case of DFIG and hybrid wind farms, the wind farms can stay connected to grid, where the variation of absorbed reactive power from the grid is very little due to the operation of $\mathrm{AC} / \mathrm{DC} / \mathrm{AC}$ converter which keeps the reactive power of DFIG independent of the output power. Also, the wind farm terminal voltage is not affected by gust wind speed variation. The effect of gust wind speed on hybrid wind farm with different capacity shows that the hybrid wind farm can stay connected to grid without STATCOM under gust wind speed condition. The AC/DC/AC converter can operate as a reactive power support during gust wind speed.

\section{REFERENCES}

[1] J.G Slootweg and W.L Kling, "Modelling and analysing of impacts of wind power on transient stability of power systems", wind engineering, Vol.25 no.6, 2001 pp320The Netherlands 2001.

[2] C. Jauch, P. SØrensen, I. Norheim, and C. Rasmussen, "Simulation of impact of wind power on the transient fault behavior of the Nordic power system", Science direct, electric power system research (77), 2007, pp 133-144.

[3] O. Noureldeen, "Characteristics of fixed speed wind turbines interconnected grid during wind speed variations", 13th Middle East Power Systems Conference MEPCON, 2009, pp. 220-225..

[4] M. N. Mansouri, M. F. Mimouni, B. Benghamen and M. Annabi, "Simulation model for wind turbine with asynchronous generator interconnected to the electric network", Science direct, Renewable energy (12), 2004 pp 1240-431.

[5] A. A. El-Sattar, N. H. Saad, M. Z. Shams El-Dien, "Dynamic response of doubly fed induction generator variable speed wind turbine", Science direct, electric power system research (78), 2008, pp 1240-1246.

[6] P.C. Krause, Analysis of Electric Machinery, McGraw-Hill Book Company, (1986).

[7] Al Jabri, A.K., Alolah, A.I., "Limits on the performance of the three phase self excited induction generators" IEEE Transactions on Energy Conversion 5 (2), June 1990, pp.350-356.

[8] J. G. Slootweg, S. W. H. de Haan, H. Polinder, and W. L. kling, "General model for representing variable speed wind turbine in power system dynamic simulation", IEEE Transactions on Power Systems 18 (1), 2008, pp 144-151. 
[9] "MATLAB/Simulink Documentation, SimPowerSystems Blockset". Available: http://www.mathworks.com.

[10] WIND TURBINE GENERATOR SYSTEMS - PART 1: Safety requirements, IEC 61400-1, 1998.

\section{تثغيل مزرعة رياح هجينة تعتمد علي المولدات الحثية ذات القفص السنجابي}

\section{والمولدات الحثية مضاعف التغذية اثناء تعرضها لعاصفة رياح}

أن الزيادة المستمرة في مستوي التلوث البيئي وفي نفس الوقت زيادة أسعار الوقود أدي إلي زيادة استخدام مصادر الطاقة المتجدة وخصوصاً طاقة الرياح. ولكن احدي التحديات الهامة هو سرعة لهرئ الرياح

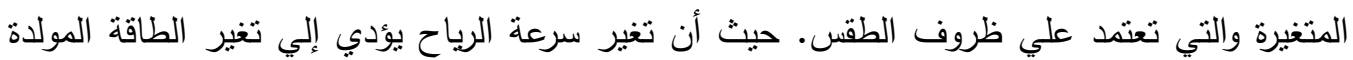

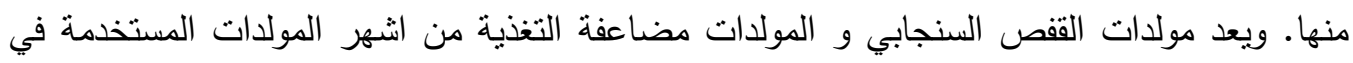

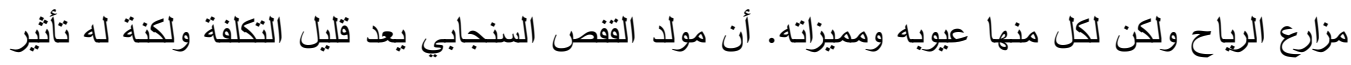
سلبي علي استقرار نظم الطاقة خصوصاً في حالة عملة بدون معوض قدرة غير فعالة تزامني. بينما فياتها

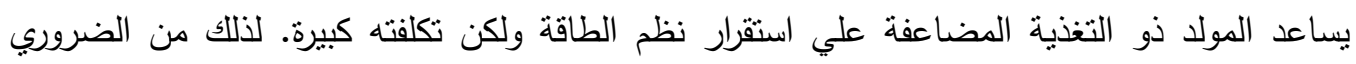
دراسة ددي استجابة أنواع المولدات المختلفة أثناء تعرضها لعاصفة رياح. في هذا نظا البحث يتم دراسة

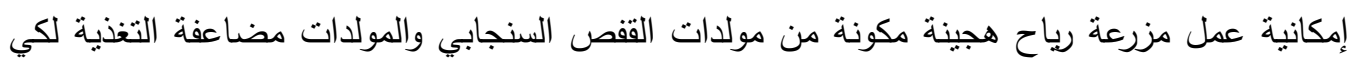

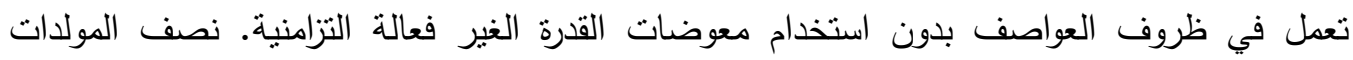
المستخدمة في المزرعة الهجينة من نوع القفص السنجابي والنصف الأخر من النوع مضاعف التغذية. في هذا البحث يتم محاكاة العاصفة بناءاً علي تقرير اللجنة الدولية الكهروتقنيه رقم 61400. 